\title{
Application of membrane-coupled sequencing batch reactor for oilfield produced water recycle and beneficial re-use
}

\begin{abstract}
Oil and gas field wastewater or produced water is a significant waste stream in the oil and gas industries. In this study, the performance of a membrane sequencing batch reactor (MSBR) and membrane sequencing batch reactor/reverse osmosis (MSBR/RO) process treating produced wastewater were investigated and compared. The MSBR was operated in different hydraulic residence time (HRT) of 8, 20 and $44 \mathrm{~h}$. Operation results showed that for a HRT of $20 \mathrm{~h}$, the combined process effluent chemical oxygen demand (COD), total organic carbon (TOC) and oil and grease (O\&G) removal efficiencies were 90.9\%, 92\% and 91.5\%, respectively. The MSBR effluent concentration levels met the required standard for oil well re-injection. The RO treatment reduced the salt and organic contents to acceptable levels for irrigation and different industrial re-use. Foulant biopsy demonstrated that the fouling on the membrane surface was mainly due to inorganic (salts) and organic (microorganisms and their products, hydrocarbon constituents) matters.
\end{abstract}

Keyword: Oilfield produced water; Re-use; Membrane; Sequencing batch reactor; Halophilic microorganisms 